\title{
RAIN MODEL - BOUNDARY CONDITION IN SEWER NETWORK APPRAISAL
}

\section{${ }^{1}$ Dušan RUSNÁK, ${ }^{2}$ Štefan STANKO, ${ }^{3}$ Ivona ŠKULTETYOVÁ}

Department of Sanitary and Environmental Engineering, Faculty of Civil Engineering, Slovak University of Technology, Radlinského 11, 81005 Bratislava, Slovakia, e-mail: ${ }^{1}$ xrusnakd@stuba.sk, ${ }^{2}$ stefan.stanko@stuba.sk, 3 ivona.skultetyova@stuba.sk

Received 18 December 2015; accepted 22 April 2016

\begin{abstract}
Appraisals results of divided and combined rain sewers highly depend on the appropriate choice of model rain. The goal of this research is to verify the impact of different rain models on results of rainfall totals, calculated flow in the network and in their overall effect on the assessment. This research focuses on three main rain models - block rain (reduced), a synthetic rain and actual historical rain with data collected from meteorological stations allocated in the area of Vráble. Historical rain event for the area has been chosen as the one with highest overall intensity with duration of at least 1 hour. Modeling process has been conducted in interface of MIKE URBAN software.
\end{abstract}

Keywords: Model rains, Sewer network, Hydraulic assessment

\section{Goals}

The goal of this study is to verify suitability and impact of the choice of different types of design model-rain in hydraulic assessment of the combined and storm sewer system. The purpose of the study is to compare the results of the various rains, their differences, compare their overall surface runoff and finally, consider which rain is most suitable for hydrodynamic models.

\section{Introduction}

While assessing combined and rain sewer networks [1] it is also necessary to include surface runoff [2]. Appropriate rain model has to be included in the correct calculation 
of surface runoff. Different models use different model rains depending on the purpose of the assessment. Rain models can be divided into three groups - historical, synthetic and block the rain. This study did not involve climate changing with future predictions [3].

Historical rain is rain episode that occurred in the recent or distant past. Their process is expressed with hyetograms measured by intensity-graphs. Unlike block rains and synthetic rains, historical rains do not have the character of 'idealized' rains and also are not characterized by the periodicity or frequency. Historical rains always represent the average values of rain intensity at selected time intervals.

Synthetic model rains with time-varying intensities simulate the variable progress of intensity running in real time during the rainy season. Synthetic rains constitute synthetic hyetograms to achieve accurate design solutions in comparison with block rains with constant intensity. This is particularly important while using more detailed computational methods that detail the superficial rain runoff and mathematically simulate non-stationary flow in the sewer network. Profile of synthetic rain is characterized by a kurtosis, defined as the ratio of the maximum intensity related to the average intensity of the entire rain event. Another important statistical parameter is the time positioning of maximum intensity in the first, second or third period duration of the synthetic rain, or in a quarter-division of its total duration.

Block model rains are the simplest but the least realistic shape of rain progress. They are often provided in the form of curves of block rain yield of certain time periods. Block rain has a constant intensity over its entire duration, therefore has a rectangular profile. It is used in the rational method having the advantage of ease of use and time saving; the disadvantage is its regular shape which cannot simulate hyetograms of real rains with variable intensities used in simulation method of runoff models [4].

\section{Problematic}

Depending on the type of assessment, there are 2 types of model rains commonly used nowadays in sewer networks assessments [5], [6]. In static methods, the block rain is usually chosen, having the advantage ease of use and being the rain chosen for designs of network with Bartošková method (modified rational method), however in hydrodynamic method, synthetic rains are more commonly used due to their closer resemblance to actual rain events. This research verifies the extent of the impact of rain selection on the outcome of assessment. This may also determine the inflow of ground water for water treatment purposes [7] as well as underground water monitoring [8].

\section{Input data}

The calculation model was made for the periodicity of $p=1$ (periodicity $p=1$ was selected in consideration of the already elapsed duration of rain events measurements in the area of Nitra and Vráble as part of the project APVV-0372-12). For the calculation of the block and synthetic rain in area Vráble, coefficients $K, B, a$ were calculated (and can be found in Table I) based on the interpolation among meteorological stations 
No. 37 - Nitra, No. 39 - Nový Tekov and No.53 - Svätuša by the formula for interpolation parameters:

$$
K_{p}=m^{-1} \cdot\left(K_{1} \cdot L_{1}^{-1}+K_{2} \cdot L_{2}^{-1}+K_{3} \cdot L_{3}^{-1}\right)
$$

where

$$
m=\left(L_{1}^{-1}+L_{2}^{-1}+L_{3}^{-1}\right) .
$$

\section{Table I}

\begin{tabular}{|c|c|c|c|c|c|c|}
\hline \multicolumn{5}{|c|}{ Interpolation input data $(p=1)$} & \multirow[b]{2}{*}{$\mathrm{L}[\mathrm{km}]$} & \multirow[b]{2}{*}{$\mathrm{m}$} \\
\hline station name & station no. & $\mathrm{K}$ & $\mathrm{B}$ & $\mathrm{a}$ & & \\
\hline Nitra & 37 & 2132.8 & 4.33 & 0.916 & 17.4 & \\
\hline Nový Tekov & 39 & 2252.3 & 4.45 & 0.928 & 16 & 0.185 \\
\hline Svätuša & 53 & 2358.0 & 4.01 & 0.927 & 15.3 & \\
\hline \multicolumn{5}{|c|}{ Results of interpolation } & & \\
\hline Vráble & - & 2252.5 & 4.26 & 0.924 & & \\
\hline
\end{tabular}

Input data and results of interpolation of $K, B, a$ parameters for area of Vráble

The value $r$ for the calculation of the synthetic rain was selected with the help of the map of isolines for the Slovak Republic (Fig. 1). Parameter $r$ is used to determine the position of the maximum intensity in which the curve changes from inclination to declination. In case of Vráble, the parameter $r=0.23$, and according to calculation, the intensity peaks is at $13^{\text {th }}$ minute and $48^{\text {th }}$ second. Calculated model-rain curves can be found in Fig. 2, Fig 3, and Fig. 4.

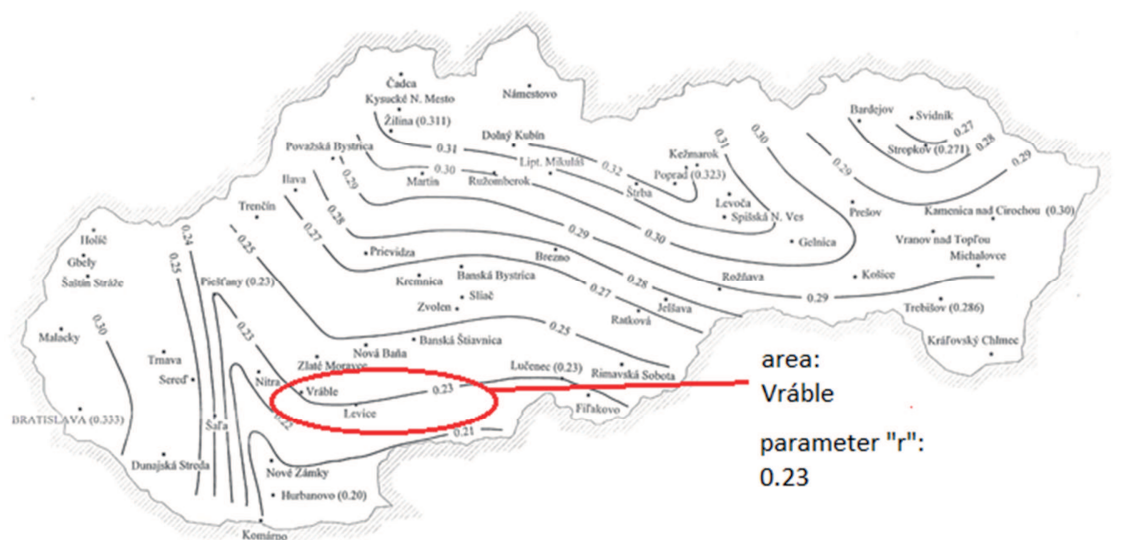

Fig. 1. Map of isolines for the Slovak Republic 
Reduced block rain curve for Vrable with periodicity of

$$
p=1
$$

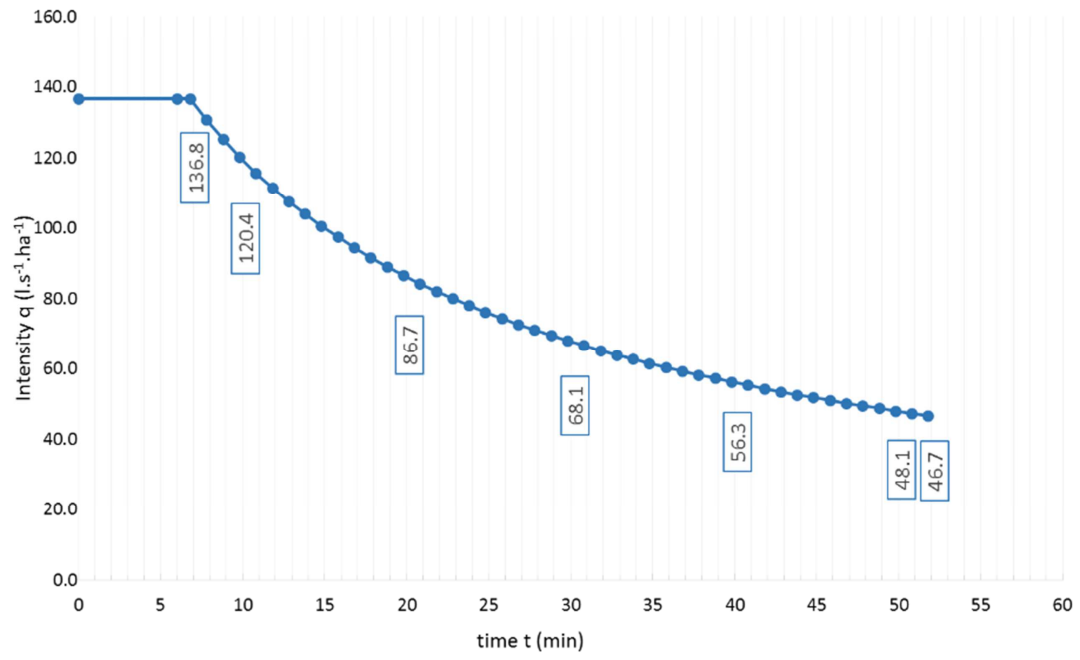

Fig. 2. Reduced block rain curve for area of Vráble with periodicity $p=1$

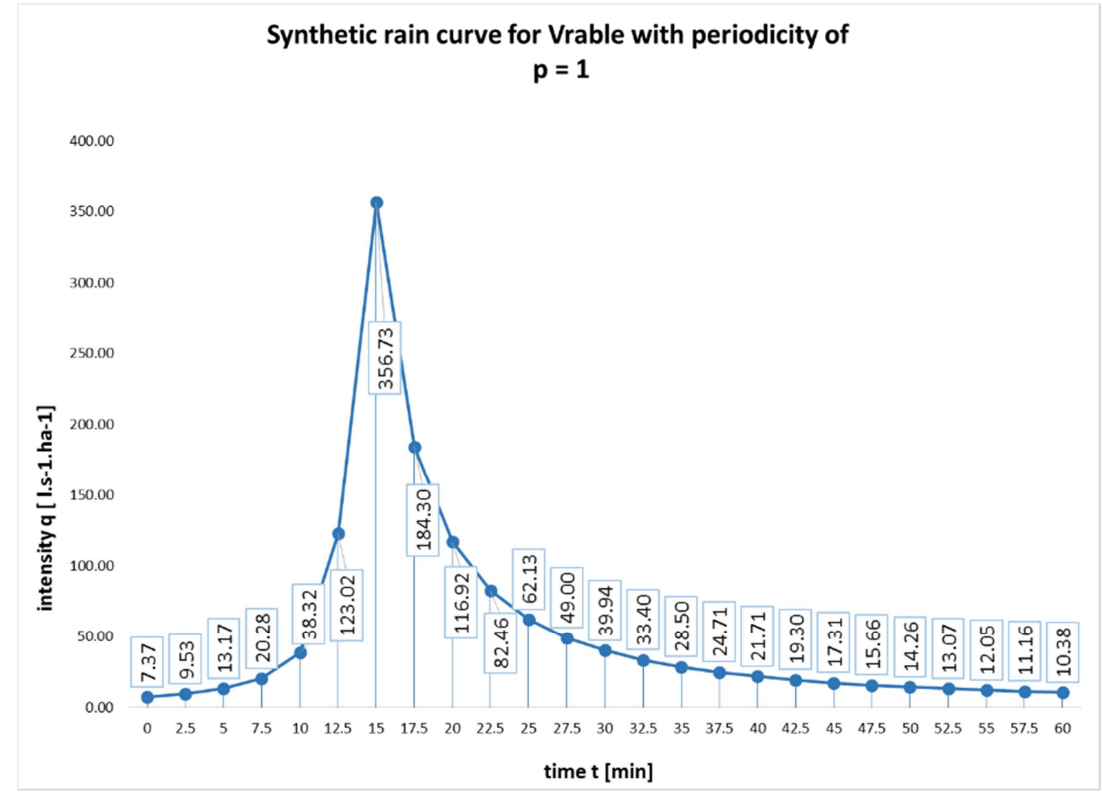

Fig. 3. Synthetic rain curve progress for area of Vráble with periodicity $p=1$ 


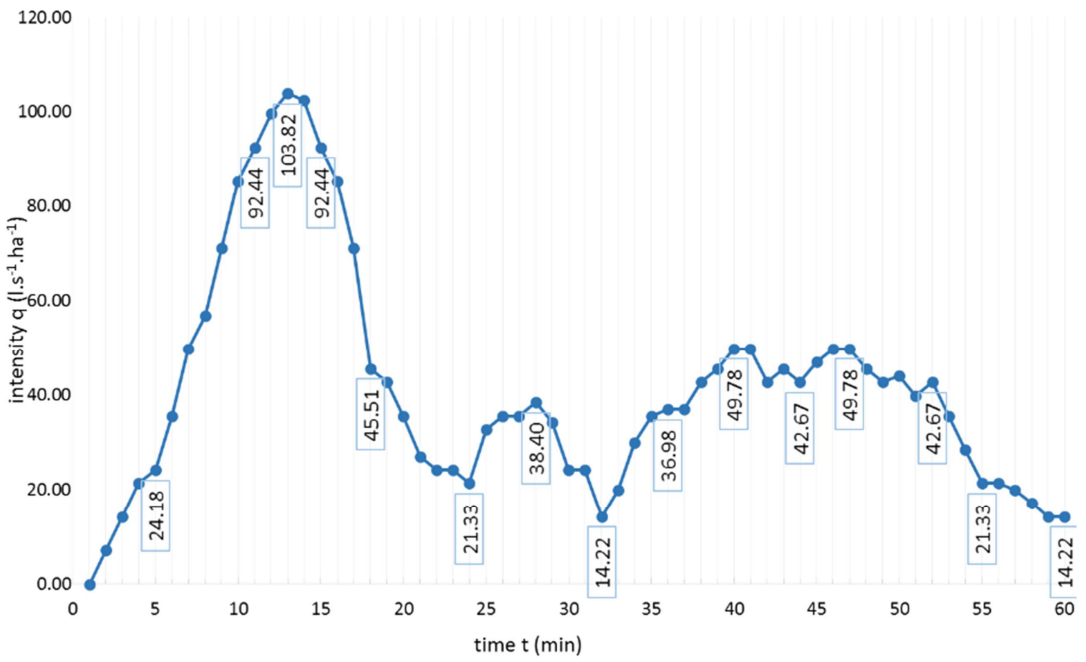

Fig. 4. Actual historical rain in area of Vráble that took place on the 21st of February 2015 between 4:37 pm and 5:37 pm

Total surface runoff amount from catchments area of 1 hectare in area of Vráble through time-span of 1 hour:

- reduced block rain: $259.82 \mathrm{~m}^{3} \cdot \mathrm{ha}^{-1}$;

- synthetic rain: $210.36 \mathrm{~m}^{3} \cdot \mathrm{ha}^{-1}$;

- historical rain: $148.56 \mathrm{~m}^{3} \cdot \mathrm{ha}^{-1}$.

\section{Simulation}

Hydraulic calculation of the sewer has been performed in MIKE URBAN. Initial comparison was focused on the maximum values of surface runoff during the entire simulation [9]. The results of the various simulations can be compared in Fig. 5 and Fig. 6 in which it is possible to see the variation of the maximum surface runoff values and total surface runoff in each sub-catchments. In case of reduced block rain, the peak intensity has been reach in 7 th minute of simulation, synthetic rain reached its peak at $4: 52 \mathrm{pm}$ (15th minute of simulation) and maximum in case of historical rain has been achieved at 4:49 pm (13th minute of simulation).

The results of processing performance of individual nodes on the sewer network using Mike URBAN databases can be found in Table II.

Results presented in the Table II show the differences among each simulation. From the total amount of 713 nodes on the network, in case of reduced block rain, $18.65 \%$ of them were overloaded. Synthetic rain simulation shown the difference of $6.6 \%$ 
compared to previous model, leaving network nodes overloaded with $25.25 \%$. Unlike reduced block rain and synthetic rain, historical rain proven to be insufficient for the comparison and according to model, only $1.54 \%$ of network nodes were overloaded during that specific rain event.

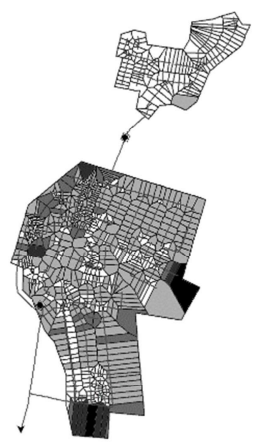

BLOCK RAIN

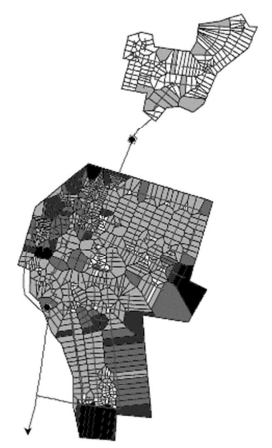

SYNTHETIC RAIN

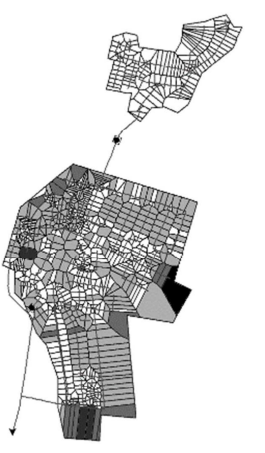

HISTORICAL RAIN $\square 0.00-0.01$

$\square$ 0.01-0.05

0.05-0.10

$0.10-0.20$

$0.20-1.00$

Fig. 5. Maximal values of surface runoff through entire duration of rain event (in $\mathrm{m}^{3} \cdot \mathrm{s}^{-1}$ )

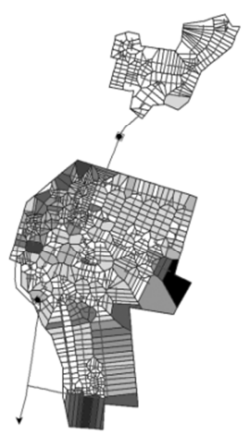

BLOCK RAIN

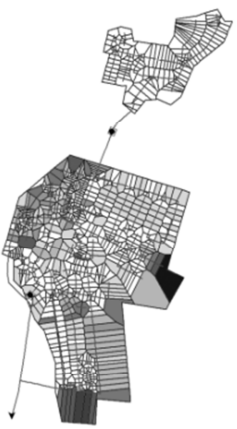

SYNTHETIC RAIN

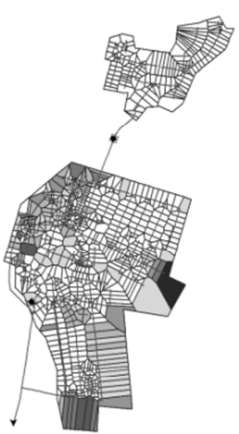

HISTORICAL RAIN $\square \quad 0.00-25.00$

$\square \quad 25.00-50.00$

$\square$ 50.00-75.00

$\square \quad 75.00-100.00$

$\square$ 100.00-150.00

150.00-250.00

- 250.00-400.00

[ 400.00-600.00

[ $600.00-800.00$

[ $800.00-1000.00$

Fig. 6. Total accumulated amount of water from surface runoff through the entire duration of rain even for each sub-catchment (in $\mathrm{m}^{3}$ )

\section{Table II}

Result summary of overloaded nodes on the network

\begin{tabular}{|l|l|l|}
\hline Type of rain & $\begin{array}{l}\text { Amount of overloaded } \\
\text { nodes }\end{array}$ & $\begin{array}{l}\text { \% of total amount of } \\
\text { nodes }\end{array}$ \\
\hline Reduced block rain & 133 & 18.65 \\
Synthetic rain & 180 & 25.25 \\
Historical rain & 11 & 1.54 \\
\hline
\end{tabular}




\section{Conclusion}

Introductory thesis research consisted in the belief that the selection of model rain in assessing sewer system has a significant impact on the outcome. Research has demonstrated variability of results for each simulation. In case of comparison of two model rains - synthetic and block rains - it is proven that the choice of the assessment does not have a significant impact on the result. The difference in results accounted only for $6.6 \%$ of a difference of overloaded nodes in total of 713 watched nodes. Assessing the area with historical rain event in this case cannot be considered sufficient from the stand point of the fact that during the reported time period (about one year), the most significant rain event had much lower intensity than the calculated intensity of the synthetic rain and even lower peak intensity than in case of block rain. In conclusion it can be said that the selection model of rain affects the outcome of the assessment, but not very significant. In hydrodynamic assessments of sewer networks such with timebased results like the ones such as MIKE URBAN, SWMM etc. where it is important to monitor the progress of pipe filling in time, it is more appropriate to choose synthetic rain for his character closer to real rain event. As for the historical - real-rain event it makes sense to assess the area only for the most intense rain event in longer time period.

\section{Acknowledgements}

Contribution was supported by the Agency for Research and Development under contract no. APVV-0372-12.

\section{References}

[1] Eggimann S., Truffer B., Maurer M. To connect or not to connect? Modeling the optimal degree of centralization for wastewater infrastructures, Water Research, Vol. 84, 2015, pp. 218-231.

[2] Peng H., Liu Y., Wang H., Ma L. Assessment of the service performance of drainage system and transformation of pipeline network based on urban combined sewer system model, Environmental Science and Pollution Research, Vol. 22, No. 20, 2015, pp. $15712-15721$.

[3] Abdelatif M., Atherton W., Alkhaddar R., Osman Y., Flood risk assessment for urban water system in a changing climate using artificial neural network, Natural Hazards, Vol. 79, No. 2, 2015, pp. 1059-1077.

[4] Urcikán P., Rusnák D. Waste water collection and treatment, Sewer networks 1, Design of sewer systems, Bratislava, Slovenská Technická Univerzita v Bratislave, 2004.

[5] Arora A. S., Reddy A. S. Conceptualizing a decentralized storm-water treatment system for an urbanized city with improper storm-water drainage facilities, International Journal of Environmental Science and Technology, Vol. 12, No. 9, 2015, pp. 2891-2900.

[6] Montserrat A., Bosch L., Kiser M. A., Poch M., Corominas L. Using data from monitoring combined sewer overflows to assess, improve, and maintain combined sewer systems, Science of the Total Environment, Vol. 505, 2015, pp. 1053-1061.

[7] Dolgosné Kovács A., Lakner G. Multi stage solution for a flexible mobile water treatment technology, Case study, Pollack Periodica, Vol. 9, No. 2, 2014, pp. 99-110. 
[8] AndrássyT., Baraková D. Numerical modeling of groundwater flow close to drinking water resources during flood events, Pollack Periodica, Vol. 11, No. 1, 2016, pp. 43-54.

[9] Chang T., Wang C., Chen A. S. A novel approach to model dynamic flow interactions between storm sewer system and overland surface for different land covers in urban areas, Journal of Hydrology, Vol. 524, 2015, pp. 662-679. 